\title{
PEMBERDAYAAN MASYARAKAT TENTANG SWAMEDIKASI MELALUI EDUKASI GEMA CERMAT DENGAN METODE CBIA
}

\author{
Musdalipah*1, Ahmad Lalo $^{2}$, Nur Saadah Daud ${ }^{1}$, Karmilah$^{1}$, Eny Nurhikmah ${ }^{1}$, \\ Khaerunnisa ${ }^{1}$, \\ Muh.Ilyas Yusuf, ${ }^{3}$ Asriullah Jabbar ${ }^{4}$, Fadliyah Malik ${ }^{4}$ \\ ${ }^{1}$ Politeknik Bina Husada Kendari, Program Studi D-III Akademi Farmasi \\ ${ }^{2}$ BPOM Kota Kendari \\ ${ }^{3}$ Politeknik Bina Husada Kendari, Program Studi D-III Analis Kesehatan \\ ${ }^{4}$ Universitas Halu Oleo, Program Studi Farmasi \\ e-mail: musdalipahapt@gmail.com
}

\begin{abstract}
Smart Community Movement Using Drugs (GEMA CERMAT) is a community movement in raising awareness and understanding of the people about the use of drugs properly and correctly. Self medication is a treatment performed by the community without using a prescription. Through GEMA CERMAT it is expected that rational use of drugs by society can be achieved, including; knowledge of composition, indication, dosage and how to use, side effects, contra indications, and drug expiration dates. The Method of mother active Learning (CBIA) is an educational model of community empowerment to be more skilled in choosing medicine so that becomes more effective, safe, and cost-effective. This activity is aimed to know the improvement of public knowledge by giving education counseling of GEMA CERMAT in choosing over-the-counter and free drug limited by CBIA method. The event was conducted at the BTN Wirabuana complex of Kendari city in May 2017 with a pretest-posttest one-group pre-experimental design. Activities using questionnaires are processed by Chi-square test. Chi-square analysis results $p=0,000<0.05$ indicate an increase in public knowledge in choosing a drug free and limited free by CBIA method.
\end{abstract}

Keywords : GEMA CERMAT, CBIA, Self Medication

\begin{abstract}
Abstrak
Gerakan Masyarakat Cerdas Menggunakan Obat (GEMA CERMAT) adalah gerakan masyarakat dalam meningkatkan kesadaran, kepedulian dan pemahaman masyarakat tentang penggunaan obat secara tepat dan benar. Swamedikasi adalah pengobatan dilakukan oleh masyarakat tanpa menggunakan resep dokter. Melalui GEMA CERMAT diharapkan penggunaan obat secara rasional oleh masyarakat dapat tercapai, meliputi ; pengetahuan komposisi, indikasi, dosis dan cara pakai, efek samping, kontra indikasi, dan tanggal kadaluarsa obat. Metode Cara Belajar Insan Aktif (CBIA) adalah model edukasi pemberdayaan masyarakat agar lebih terampil memilih obat sehingga swamedikasi menjadi lebih efektif, aman, dan hemat biaya. Kegiatan ini bertujuan untuk mengetahui peningkatan pengetahuan masyarakat dengan pemberian penyuluhan edukasi GEMA CERMAT dalam memilih obat bebas dan obat bebas terbatas dengan metode CBIA. Kegiatan dilakukan di kompleks BTN Wirabuana kota Kendari pada bulan Mei 2017 dengan desain pra-experimental one-group pretest-posttest. Kegiatan menggunakan kuesioner yang diolah dengan uji Chi-square. Hasil analisis Chi-square p=0,000 $<0,05$ menunjukkan adanya peningkatan pengetahuan masyarakat dalam memilih obat bebas dan bebas terbatas dengan metode CBIA.
\end{abstract}

Kata kunci : GEMA CERMAT, CBIA, Swamedikasi 


\section{PENDAHULUAN}

Pengobatan sendiri, atau yang disebut swamedikasi merupakan upaya yang paling banyak dilakukan mayarakat untuk mengatasi gejalah penyakit sebelum mencari pertolongan dari tenaga kesehatan [1]. Berdasarkan survey Sosial Ekonomi Nasional (SUSENAS) menunjukkan bahwa lebih dari 66\% masyarakat melakukan pengobatan sendiri (swamedikasi). Sedangkan Hasil Riset Kesehatan Dasar tahun 2013 menunjukkan 35,2\% masyarakat Indonesia menyimpan obat dirumah , baik diperoleh dari resep dokter maupun dibeli sendiri secara bebas. Proporsi masyarakat yang menyimpan obat keras tanpa resep mencapai $81,9 \%$, diantaranya termasuk antibiotik [2]. Data ini membuktikan bahwa sejumlah besar masyarakat melakukan swamedikasi, untuk itu harus diimbangi dengan informasi yang memadai, sehingga tidak terjadi kesalahan.

Cara Belajar Insan Aktif (CBIA) adalah metode pendidikan masyarakat yang berorientasi pada peran aktif peserta didik dalam mencari informasi, dan menumbuhkan sikap serta mengubah perilaku. Informasi tersebut berguna bagi masyarakat antara lain agar mampu mempertimbangkan promosi iklan obat di pasaran dan mengelola obat di rumah tangga secara benar, selain itu juga agar tujuan penggunaan obat secara rasional dapat tercapai secara optimal dalam melakukan swamedikasi [1]. Hasil Penelitian Musdalipah dkk menunjukkan bahwa ada hubungan yang bermakna pemberian metode CBIA terhadap peningkatan pengetahuan ibu hamil dalam memilih obat bebas di Puskesmas Perumnas Kota Kendari [3].

Swamedikasi menjadi alternatif yang diambil masyarakat untuk meningkatkan keterjangkauan pengobatan. Apoteker bisa memberi informasi yang objektif dan rasional, swamedikasi yang baik dan bertanggungjawab dapat memberikan banyak manfaat bagi pasien. Pada pelaksanaannya swamedikasi dapat menjadi sumber terjadinya kesalahan pengobatan (medication error) karena keterbatasan pengetahuan masyarakat akan obat dan penggunaannya. Oleh sebab itu, perlu dicapai pengetahuan yang benar mengenai penggunaan obat-obat yang baik dan benar sesuai dengan cara penggunaannya melalui peningkatan GEMA CERMAT.

GEMA CERMAT atau Gerakan Masyarakat Cerdas Menggunakan Obat adalah gerakan masyarakat dalam meningkatkan kesadaran, kepedulian dan pemahaman masyarakat tentang penggunaan obat secara benar. Gerakan ini merupakan upaya bersama antara pemerintah dan masyarakat melalui rangkaian kegiatan dalam rangka mewujudkan kepedulian, kesadaran, pemahaman dan keterampilan masyarakat dalam menggunakan obat secara tepat dan benar [4]. Strategi edukasi dan pemberdayaan masyarakat, melalui GEMA CERMAT diharapkan mampu meningkatkan penggunaan obat rasional pada masyarakat. Kegiatan pengabdian kepada masyarakat dilakukan untuk mengetahui tingkat pengetahuan dan ketepatan swamedikasi pada masyarakat dengan metode CBIA.

\section{METODE}

Kegiatan pengabdian masyarakat dilakukan dengan 3 tahapan, yaitu 1) memberikan kuesioner (pretest) untuk mengetahui pengetahuan sebelum penyuluhan, 2) Penyuluhan Gema Cermat dengan metode CBIA. Kegiatan penyuluhan dibagi menjadi 7 kelompok dengan 7 narasumber sebagai fasilitator. Memberikan sosialisasi tentang GEMA CERMAT dengan cara membagi 3 kegiatan. Masing-masing kelompok yang terdiri dari 10 orang yang akan diberikan 1 paket obat yang terdiri dari bermacam-macam jenis, kemudian dilakukan kegiatan : Kegiatan I (kelompok) : Mengamati kemasan obat (mengenali nama dagang, mengenali bahan aktif, mengenali kekuatan bahan aktif dan mengenali bahan utama dan tambahan pada obat kemasan). Menegelompokkan obat berdasarkan jenis bahan aktif bukan berdasarkan indikasi Mendiskusikan hasil pengamatan. Kegiatan II (kelompok) : Mengumpulkan informasi yang sebagai dasar melakukan self-medication, yaitu : nama bahan aktif, indikasi, aturan penggunaan, efek samping dan kontraindikasi. Kegiatan III : Kegiatan ini bertujuan untuk memupuk keberanian masyarakat untuk mencari informasi sendiri. Setelah menjelaskan 3 kegiatan, ditutup dengan rangkuman oleh narasumber dan memberikan pesan-pesan untuk memperkuat dampak intervensi. Dilakukan posttest dengan membagikan kuesioner kepada masyarakat untuk mengetahui bagaimana pengaruh edukasi Gema Cermat terhadap pengetahuan masyarakat BTN wirabuana tentang swamedikasi. 
Dilakukan evaluasi kuesioner pretest dan posttest. Dikelompokkan data berdasarkan hasil dari kuesioner, serta memberi skor.

\section{HASIL DAN PEMBAHASAN}

Kegiatan pengabdian kepada masyarakat dilaksanakan di Kompleks BTN Wirabuana kota Kendari karena Masyarakat dikompleks BTN Wirabuana selalu menggunakan swamedikasi dalam mengatasi keluhan penyakit yang dideritanya. Kegiatan ini melibatkan 30 orang ibu-ibu BTN Wirabuana dan 8 orang sebagai fasilitator. Swamedikasi merupakan salah satu upaya yang sering dilakukan oleh seseorang dalam mengobati gejala sakit atau penyakit yang sedang dideritanya tanpa terlebih dahulu melakukan konsultasi kepada dokter. Namun penting untuk dipahami bahwa swamedikasi yang tepat, aman,dan rasional tidak dengan cara mengobati tanpa terlebih dahulu mencari informasi umum yang bisa diperoleh tanpa harus melakukan konsultasi dengan pihak dokter. [5]. Pada pelaksanaannya swamedikasi dapat menjadi sumber terjadinya kesalahan pengobatan (medication error) karena keterbatasan pengetahuan masyarakat akan obat dan penggunaannya. Oleh sebab itu, kegiatan ini perlu dilakukan karena untuk mencapai pengetahuan yang benar mengenai penggunaan obat-obat yang tepat dan benar melalui edukasi GEMA CERMAT.

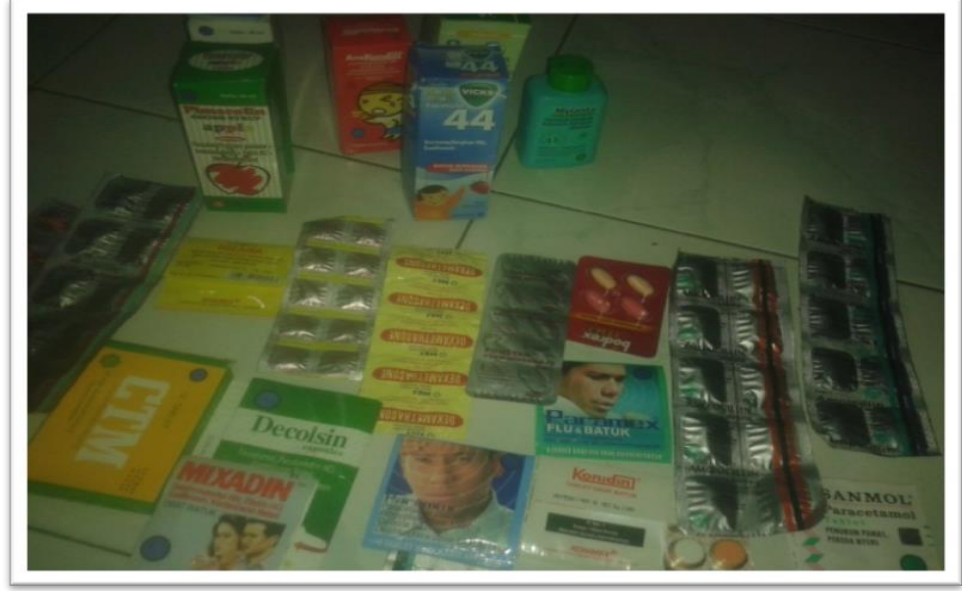

Gambar 1. Alat Peraga Obat-obatan GEMA CERMAT

Karakteristik masyarakat BTN Wirabuana dapat dilihat pada tabel dibawah ini :

Tabel 1 Distribusi Responden Berdasarkan Pendidikan di Kompleks BTN Wirabuana Kota Kendari

\begin{tabular}{cccc} 
No & Pendidikan & Frekuensi (F) & Presentase (\%) \\
\hline 1 & S1 & 17 & $56,67 \%$ \\
\hline 2 & D3 & 1 & $3,33 \%$ \\
\hline 3 & D2 & 1 & $3,33 \%$ \\
\hline 4 & SMA & 11 & $36,67 \%$ \\
\hline & Jumlah & 30 & $100 \%$
\end{tabular}

Kegiatan GEMA CERMAT dibagi dalam tiga tahap yaitu :

\section{Pretest}

Kegiatan GEMA CERMAT dilaksanakan oleh organisasi profesi Ikatan Apoteker Indonesia (IAI) Cabang kendari bekerja sama dengan dosen politeknik bina husada Kendari. Untuk jalannya kegiatan dibagi menjadi 3 tahap, yaitu pretest, intervensi dan posttest menggunakan kuesioner. Tahap pretest, dilakukan dengan membagikan kuesioner pada 
masyarakat BTN Wirabuana. Setelah dilakukan pengambilan data pada saat pretest responden akan diberikan sosialisasi tentang penggunaan obat secara baik dan benar melalui edukasi GEMA CERMAT dengan metode CBIA, yaitu berupa diskusi yang dilakukan dengan membagi 8 kelompok yang terdiri dari 3-4 orang dimana apoteker sebagai narasumber untuk mendampingi sekaligus memberikan pemahaman tentang penggunaan obat secara rasional. setelah dilakukannya diskusi, responden diminta kembali mengisi lembar kuesioner atau posttest.

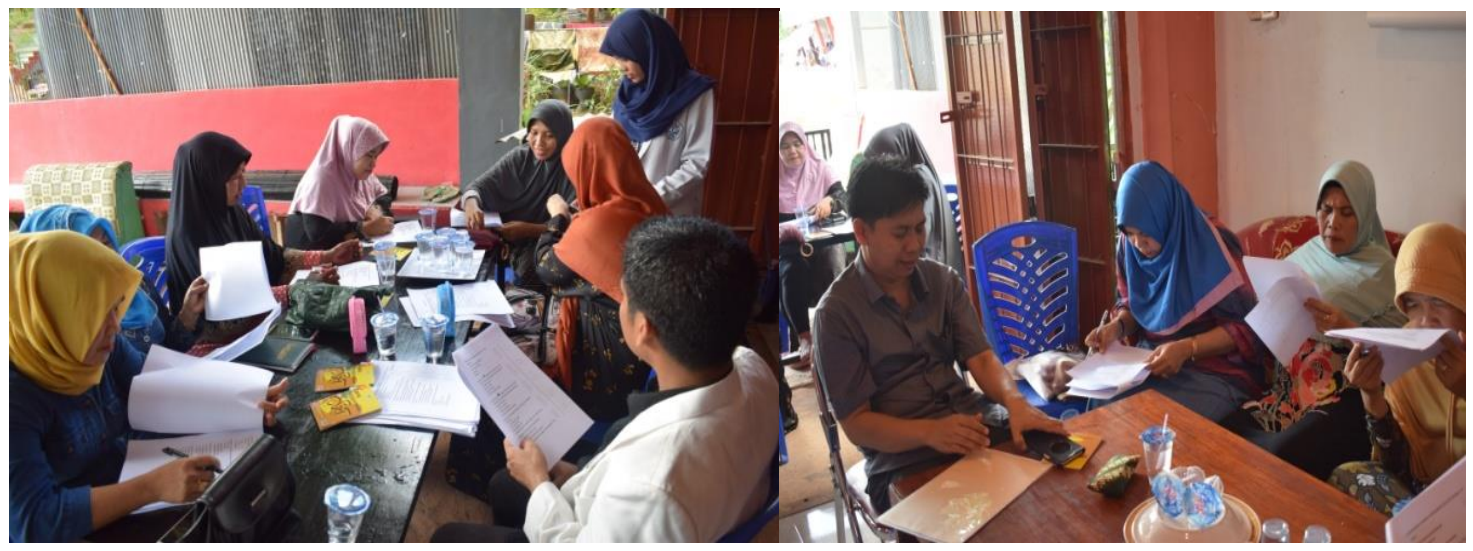

Gambar 2. Kegiatan Pretest

Berdasarkan hasil uji pretest pada warga BTN Wirabuana Kota Kendari dapat diperoleh hasil sebagai berikut :

Tabel 2. Distribusi Responden Berdasarkan Pengetahuan saat Pretest Di Kompleks BTN Wirabuana Kota Kendari

\begin{tabular}{ccc}
\hline Pengetahuan & Frekuensi (F) & Presentase (\%) \\
\hline Baik & 4 & $13,33 \%$ \\
\hline Kurang & 26 & $86,67 \%$ \\
\hline Jumlah & 30 & $100 \%$ \\
\hline
\end{tabular}

Tabel 2 menunjukkan bahwa pengetahuan masyarakat BTN Wirabuana kategori baik hanya 4 orang $(13,33 \%)$ dan kurang sebanyak 26 orang $(86,67 \%)$. Hal ini menunjukkan bahwa pengetahuan masyarakat tentang swamedikasi masih kurang.

\section{Intervensi GEMA CERMAT dengan metode CBIA}

Dalam kegiatan ini masyarakat diminta untuk mengamati dibagian mana dari kemasan yang mencantumkan bahan aktif (bahan atau kandungan komponen utama suatu obat) lalu mengenali bagaimana cara menuliskan bahan aktif obat tersebut, masyarakat juga harus bisa menemukan dan membaca dengan teliti hal - hak penting seperti indikasi, komposisi baik kandungan isi maupun kekuatan sediaan, bentuk sediaan, efek samping, kontra indikasi, aturan pakai, tanggal kadaluarsa hingga penggolongan obat. Semua hasil dari diskusi pengelompokkan obat tersebut dicatat dalam selembar kertas yang telah disiapkan. Apoteker akan menganalisa dan mendiskusikannya dengan masyarakat, dimana masyarakat bisa saling berinteraksi menyampaikan penemuannya dan saling memberi masukan serta pertanyaan untuk didiskusikan. Hal ini dilakukan agar masyarakat dapat mengumpulkan informasi yang menjadi dasar untuk melakukan swamedikasi sehingga bisa menggunakan obat dengan tepat, tidak cukup hanya melihat merek dan indikasinya saja.

Metode Cara Belajar Ibu Aktif (CBIA) merupakan salah satu kegiatan pemberdayaan masyarakat yang dapat digunakan untuk swamedikasi [3]. Hal ini sesuai teori ketrampilan ibu dalam pemilihan obat, menyatakan bahwa metode CBIA dapat terbukti efektif untuk meningkatkan pengetahuan dan ketrampilan para ibu peserta dalam pemilihan obat, dan 
dapat meningkatkan efisiensi penggunaan obat dalam rumah tangga dan kegiatannya disukai oleh para peserta [6].

Manfaat dari edukasi GEMA CERMAT ini yaitu agar masyarakat untuk meningkatkan pemahaman dan kesadaran masyarakat tentang pentingnya menggunakan obat dengan benar, meningkatkan kemandirian dan perubahan perilaku masyarakat dalam memilih dan menggunakan obat secara benar, dan akhirnya akan meningkatkan penggunaan obat secara rasional, Kelebihan atau keunggulan dari edukasi GEMA CERMAT ini adalah tidak membosankan, karena terjadi dialog interaktif antara masyarakat dan narasumber sehingga membuat masyarakat lebih cepat memahami apa yang dijelaskan oleh narasumber, serta saling berbagi ilmu dan pengetahuan dalam memilih obat bebas dan obat bebas terbatas yang berarti terdapat pengaruh dari edukasi GEMA CERMAT terhadap pengetahuan masyarakat dalam memilih dan membeli obat diapotik atau toko obat.

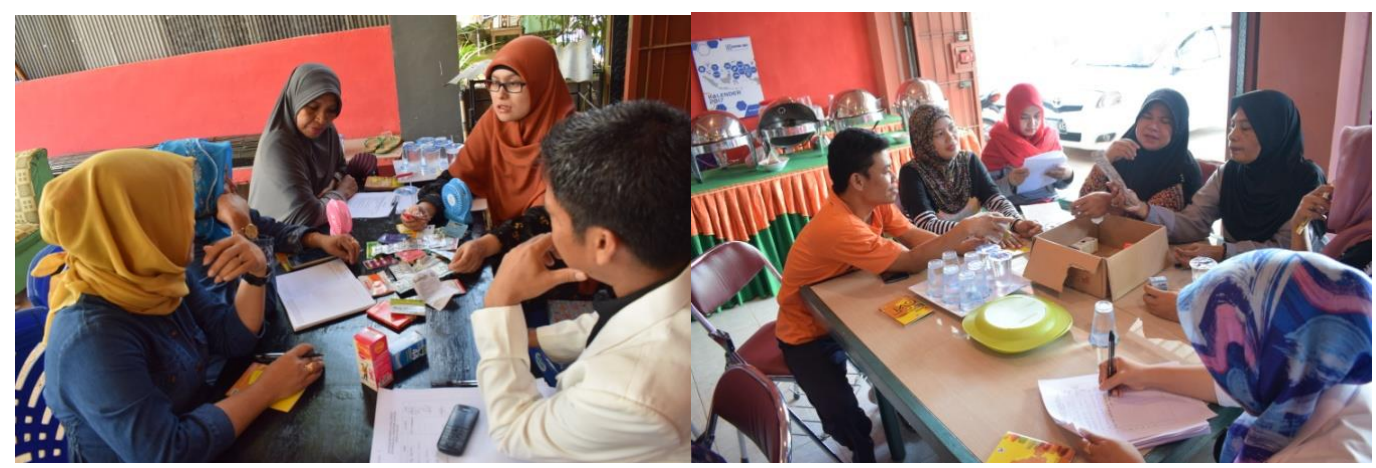

Gambar 3. Edukasi GEMA CERMAT

Pada akhir kegiatan dilaksanakan penyerahan hadiah pada ibu-ibu yang aktif pada saat edukasi GEMA CERMAT. Semua ibu-ibu sangat antusias mengikuti kegiatan ini, karena pada saat penyuluhan aktif memberikan pertanyaan terkait masalah penggunaan obat dan penyakit yang diderita.

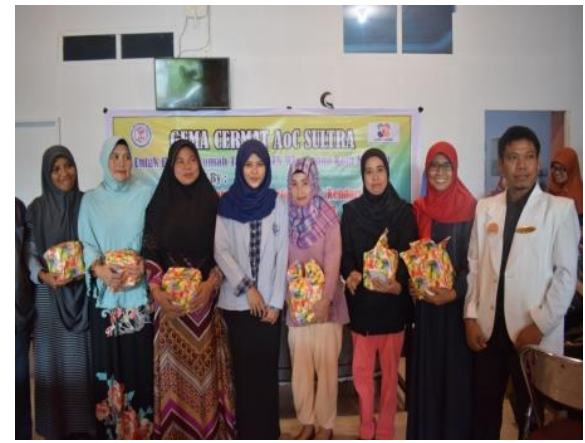

Gambar 4. Proses Penyerahan Hadiah

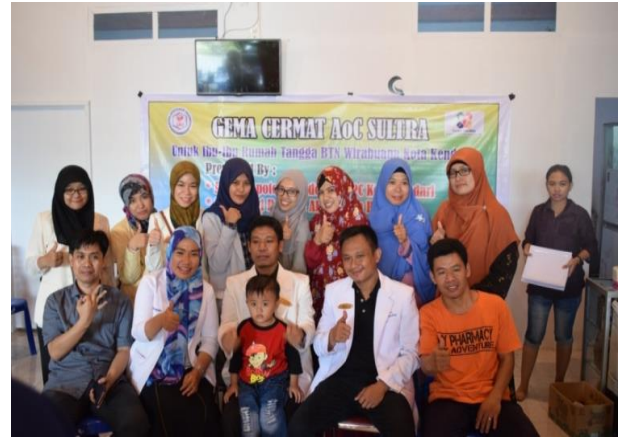

Gambar 5. Tim Fasilitator GEMA CERMAT 


\section{Kegiatan Posttest}
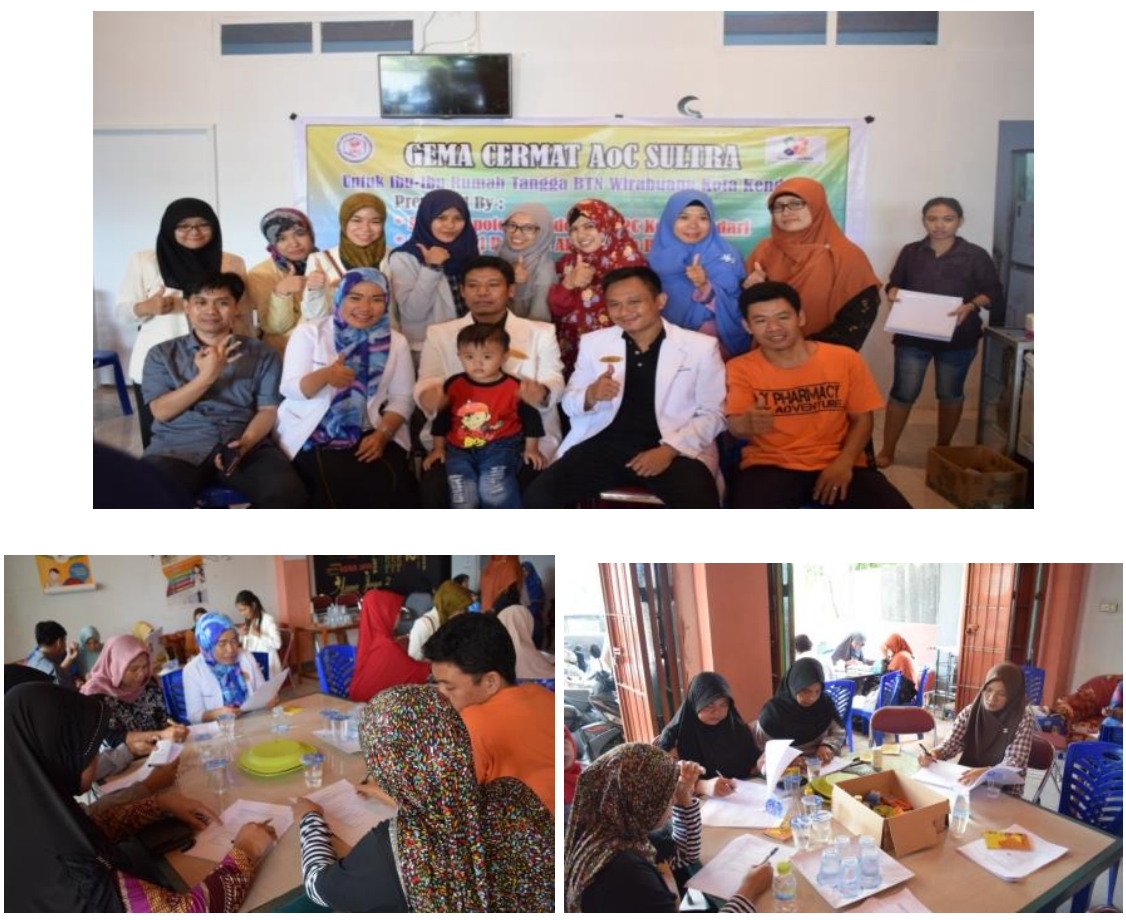

Gambar 6. Kegiatan Posttest

Tabel 3. Distribusi Pengetahuan saat Posttest di Kompleks BTN Wirabuana Kota Kendari

\begin{tabular}{ccc}
\hline Pengetahuan & Frekuensi (F) & Presentase (\%) \\
\hline Baik & 30 & $100 \%$ \\
\hline Kurang & 0 & $0 \%$ \\
\hline Jumlah & 30 & $100 \%$ \\
\hline
\end{tabular}

Tabel 3 menunjukkan bahwa pada saat posttest, kategori pengetahuan baik sebanyak 30 orang $(100 \%)$ responden. Data diatas menunjukkan responden dengan kategori baik meningkat menjadi 100\%. Hal ini membuktikan bahwa edukasi GEMA CERMAT ini sangat efektif untuk meningkatkan pengetahuan masyarakat mengenai penggunaan obat secara rasional khususnya obat bebas dan obat bebas terbatas. Masyarakat kompleks BTN Wirabuana dapat memahami dan serta dapat meningkatkan kemandirian dan perubahan perilaku dalam memilih dan menggunakan obat secara benar, dan akan meningkatkan penggunaan obat secara rasional sehingga mutu pelayanan kesehatan dapat ditingkatkan.

Tabel 4. Analisis Uji Chi-square edukasi GEMA CERMAT terhadap Pengetahuan Masyarakat Kompleks BTN Wirabuana Kota Kendari

\section{Posttest}

\section{Pengetahuan}

$$
\text { F } \quad \% \quad \text { F } \quad \% \quad \text { Nilai }(p=\text { value })
$$

$\begin{array}{llllll}\text { Baik } & 4 & 13,33 \% & 30 & 100 & 0,000<0,05\end{array}$




\begin{tabular}{ccccc}
\hline Kurang & 26 & $86,67 \%$ & 0 & 0 \\
\hline Jumlah & 30 & $100 \%$ & 30 & 100 \\
\hline
\end{tabular}

Hasil uji Chi-Square pada posttest diperoleh nilai $\mathrm{p}=0,000<0,05$ yang berarti ada hubungan atau pengaruh yang bermakna antara pemberian edukasi GEMA CERMAT terhadap pengetahuan masyarakat dalam memilih obat bebas dan bebas terbatas. Pemberian edukasi GEMA CERMAT terhadap masyarakat memberikan efek atau dampak positif bagi dunia kesehatan, khususnya pada sektor kesehatan masyarakat sehingga dapat dilanjutkan dan dikembangkan penyuluhan dengan edukasi GEMA CERMAT. Salah satu menjadi faktor penyebab terjadinya peningkatan pengetahuan karena antusiasme dan rasa ingin tahu dari masyarakat mengenai obat - obatan cukup besar sehingga masyarakat lebih mudah memahami mengenai obat bebas dan obat bebas terbatas.

\section{KESIMPULAN}

1. Edukasi GEMA CERMAT dengan metode CBIA dapat meningkatkan pengetahuan masyarakat tentang swamedikasi.

2. Hasil analisis Chi-square $\mathrm{p}=0,000<0,05$ menunjukkan adanya peningkatan pengetahuan masyarakat tentang swamedikasi melalui edukasi GEMA CERMAT dengan metode CBIA.

\section{SARAN}

Agar dilakukan penelitian mengenai edukasi GEMA CERMAT terhadap pengetahuan masyarakat khusus obat-obatan antibiotik.

\section{UCAPAN TERIMA KASIH}

Penulis mengucapkan terima kasih kepada seluruh pengurus Ikatan Apoteker Indonesia (IAI) Kota Kendari yang telah memberi dukungan kegiatan ini.

\section{DAFTAR PUSTAKA}

[1] Departemen Kesehatan Republik Indonesia. 2008, Materi Pelatihan Peningkatan Pengetahuan Dan Keterampilan Memilih Obat Bagi Tenaga Kesehatan. Jakarta: Departemen Kesehatan Republik Indonesia.

[2] Kementerian Kesehatan Republik Indonesia. 2013, Riset Kesehatan Dasar. Jakarta: Kementerian Kesehatan Republik Indonesia.

[3] Musdalipah, Wahid Ado, Prasetyo, 2016, Peningkatan Pengetahuan Ibu Hamil Memilih Obat Bebas Menggunakan Metode CBIA (Cara Belajar Insan Aktif), Jurnal Ilmiah Ibnu Sina, 1(2) : $219-226$

[4] Kementerian Kesehatan Republik Indonesia. 2015, SK Menteri Kesehatan RI Nomor HK.02.02/MENKES/427/2015 tentang Gerakan Masyarakat Tentang Penggunaan Obat. www.depkes.go.id

[5] Depkes RI, 2006, Pedoman Penggunaan Obat Bebas dan Obat Terbatas. Departement Kesehatan Repuplik Indonesia, Jakarta

[6] Suryawati S. CBIA: Improving the Quality of Self Medication through Mothers Active Learning. In: World Health Organization (Ed). Essensial Drugs Monitor No. 32. Geneva: World Health Organization; 2003 